\title{
Revista
}

Triângulo

\section{PRÁTICAS CULTURAIS DE PUÉRPERAS NO ALEITAMENTO MATERNO: PROBLEMAS MAMÁRIOS ${ }^{1}$}

\section{CULTURAL PRACTICES OF MOTHERS WHO IN BREASTFEEDING: BREAST PROBLEMS}

\author{
Stefanie Koch da Rocha ${ }^{2}$ e Ana Paula Xavier Ravelli ${ }^{3}$
}

\begin{abstract}
RESUMO
Este estudo objetivou identificar as práticas culturais utilizadas por puérperas atendidas pelo projeto CPE frente aos problemas mamários no decorrer do aleitamento materno. Trata-se de pesquisa qualitativa descritiva, realizada em uma maternidade na cidade de Ponta Grossa. Coleta de dados ocorreu por entrevista semi-estruturada e após realizou-se a transcrição e análise de conteúdo das falas, onde surgiram as categorias norteadoras. Foram descritas práticas culturais relacionadas aos traumas mamilares, ingurgitamento mamário, mamilos invertidos, assim como práticas realizadas para aumentar a quantidade de leite produzida, demonstrando assim a significativa influência que o meio sócio-cultural desenvolve no cuidado cotidiano da puérpera frente aos cuidados com a mama. Concluise assim que é necessário que o enfermeiro saiba reconhecer a influencia das praticas culturais no manejo dos problemas mamários, orientando de forma a unir os conhecimentos científicos aos saberes populares, para que a puérpera saiba reconhecer as práticas que podem contribuir negativamente em sua saúde. Além disso, é importante superar a visão da amamentação como dever materno determinado pela biologia feminina, cabendo ao enfermeiro oferecer suporte tanto ao problema das mamas, como emocional, diminuindo a ansiedade e medo.
\end{abstract}

Palavras-chave: Educação em Saúde. Aleitamento Materno. Cultura.

\begin{abstract}
This study aimed to identify the cultural practices used by women who have recently given birth assisted by the CPE project to cope with breast maladies during breastfeeding. The study is a descriptive qualitative research, conducted in a maternity in the city of Ponta Grossa. The data was collected by means of semi-structured interviews, which were transcribed and analyzed to create guiding categories. The cultural practices described were related to breast trauma, breast swelling, inverted nipples, as well as practices to increase milk production, demonstrating thus the meaningful influence of social-cultural aspects in the daily breast care of women by who have recently given birth. Therefore, it is necessary for the nurse to recognize the influence of cultural practices in daily breast care, giving orientations that combine both scientific knowledge and popular myth so that women can detect practices that can be detrimental to one's own health. It is also important to overcome the notion as a maternal duty determined by female biology, being the nurse's task to provide support to both breast and emotional problems, decreasing anxiety and fear.
\end{abstract}

Keywords: Health Education. Breast Feeding. Culture.

\footnotetext{
${ }^{1}$ Artigo desenvolvido como trabalho de conclusão de curso em Bacharelado em Enfermagem pela Universidade Estadual de Ponta Grossa (UEPG).

${ }^{2}$ Enfermeira Residente pela Residência Multiprofissional no Programa Saúde da Mulher, Hospital de ClínicasUniversidade Federal do Paraná (HC-UFPR). Email: stefy.koch@ hotmail.com

${ }^{3}$ Doutora em Enfermagem, Professora Adjunta do Departamento de Enfermagem e Saúde Pública da Universidade Estadual de Ponta Grossa. Coordenadora do Consulta Puerperal de Enfermagem. Email: anaprx@hotmail.com
} 


\section{INTRODUÇÃO}

Indiscutível e inquestionável é a importância do Aleitamento Materno (AM), tanto para recém-nascido, quanto para a mulher que amamenta, compreendendo que a amamentação é o principal meio de fornecer alimento adequado e ideal, pois além de alimentar e nutrir, o leite materno promove o crescimento saudável, formação do vínculo afetivo e defesa contra as diversas doenças infecciosas da infância e doenças crônicas, da vida adulta (BRASIL, 2011). A prática do aleitamento materno para a mulher contribui na retração uterina durante o período de pós-parto imediato e mediato, proteção contra o câncer de mama, auxílio no restabelecimento do peso pré-gestacional e ainda economia para a família (BRASIL, 2011; MARQUES, COTTA E PRIORE, 2011).

A recomendação é que as crianças recebam leite materno exclusivo, até os seis meses, não sendo necessária a complementação da alimentação com leite artificial ou de vaca, uso de chás ou água. Após os seis meses, recomenda-se que as mães, além do leite materno ofereçam outros alimentos, a fim de suprir as necessidades corporais, nutricionais e metabólicas da criança, permanecendo então o aleitamento até os dois anos ou mais (BRASIL, 2009).

Entretanto, diversos estudos (ARAUJO et al., 2008; MONTEIRO, NAKANO, GOMES, 2011) demonstram que a prática de amamentar é abandonada precocemente devido às várias intercorrências, apontando algumas causas para o desmame precoce, sendo as enfermidades maternas, e por consequência o uso de medicamentoso ocorrendo a substituição do AM pelo leite artificial, bem como, a pouca produção de leite ou baixa qualidade do leite materno, são as principais justificativas.

A amamentação é muitas vezes imposta às mulheres como um dever, um ato biologicamente determinado, devido os atributos físicos que permitem a mulher desenvolver a função materna (MONTEIRO, NAKANO, GOMES, 2011). Porém o ato de amamentar não é instintivo nos humanos, tornando-se assim facilmente influenciada por valores culturais, históricos e sociais do meio vivido (MARQUES, COTTA E PRIORE, 2011).

No que se refere a cultura, é possível verificar a existência de diversas interpretações deste termo, portanto para este estudo, a cultura será abordada como o conhecimento humano adquirido através da acumulação das experiências das gerações anteriores, a qual é responsável por moldar o comportamento e ações humanas. Desta forma, conclui-se que o homem é o produto do meio sócio-cultural no qual foi educado, sendo então o responsável 
pela propagação dos conhecimentos, valores e crenças do ambiente em que vive (LARAIA, 2001).

Através do cuidado no ambiente familiar é possível identificar a transmissão dos costumes e comportamentos da cultura local, principalmente pelas mulheres, as quais são responsáveis pelo cuidado familiar, caracterizando assim as práticas culturais. Entre as quais se podem citar a pratica de guardar o coto umbilical para então a criança vir a ter sorte; o uso de roupas no seu lado avesso fazendo com que a criança permaneça acordada durante o dia e durma bem à noite; e o uso de um pequeno pedaço de lã na testa da criança para o alívio dos soluços (TOMELERI, MARCON, 2009).

Nessa perspectiva frente à prática do AM, a mãe vivencia o período pós-parto ou puerpério, no qual é envolto de diversas dúvidas, crenças, mitos e fatores culturais no cuidado com o recém-nascido, sendo neste período, a transmissão das práticas culturais no cuidado, transmitida entre as gerações (TOMELERI, MARCON, 2009).

Diante do surgimento dos problemas mamários, a puérpera fica vulnerável e exposta a solucionar através da cultura popular os problemas decorrentes da amamentação. Dessa forma é importante que os profissionais de saúde estejam familiarizados com as práticas populares e culturais da população, para então poder oferecer de forma eficaz uma solução para o enfrentamento dos problemas mamários. Sendo assim, cabe ao enfermeiro a responsabilidade, de identificação dos problemas relacionados a amamentação e elaboração de assistência planejada, considerando o contexto cultural de vivência da puérpera e seus comportamentos, para que assim possa realizar intervenções educativas individualizadas, focando as necessidades da mulher (MARQUES, COTTA E PRIORE, 2011; VIEIRA et al, 2010).

Mediante formação acadêmica e participação no Projeto Consulta Puerperal de Enfermagem (CPE), pela Universidade Estadual de Ponta Grossa, pude perceber que apesar dos diversos incentivos e campanhas promovendo o aleitamento materno, frequentemente se observa a ocorrência do desmame precoce, causado pelos problemas mamários, além de observar a falta da realização da educação em saúde, permitindo que práticas culturais sejam utilizadas pelas mulheres/família, acarretando em outros riscos a sua saúde pois não houve discernimento e aprendizado, portanto, não há promoção do autocuidado materno. Desta forma, esta pesquisa tem por objetivo identificar as práticas culturais utilizadas por puérperas atendidas pelo projeto CPE frente aos problemas mamários no decorrer do aleitamento materno. 


\section{METODOLOGIA}

Trata-se de pesquisa qualitativa descritiva, que busca a obtenção de dados descritivos, mediante o contato direto do pesquisador com o ambiente e objeto estudado, bem como a compreensão do significado dos atos e intenções do ser humano. $\mathrm{O}$ pesquisador busca a compreensão de fenômenos a partir da visão dos participantes de uma determinada situação, e então estabelece a interpretação do fenômeno pesquisado (NEVES, 1996).

A coleta dos dados ocorreu mediante entrevista semi-estruturada, com questões norteadoras sobre as práticas culturais utilizadas por mulheres no cuidado com as mamas frente ao surgimento de problemas mamários no período pós-parto (APENDICE A). As entrevistas foram gravadas em formato digital, conforme aspectos éticos, e posteriormente transcritas no Microsoft Office, Word 2007 para análise e categorização.

Participaram do estudo 11 mulheres que estavam vivenciando o período puerperal e foram atendidas pelo Projeto Consulta Puerperal de Enfermagem (CPE), no período de 15 de maio a 25 de julho de 2012. Como critérios de inclusão, puérperas atendidas pelo projeto CPE que apresentavam algum problema mamário no decorrer da sua internação no local do estudo e como critérios de exclusão, as puérperas atendidas pelo projeto CPE que não apresentavam nenhum problema mamário e as demais puérperas que não participaram do projeto.

A coleta ocorreu em um Hospital e Maternidade de referência para o atendimento da gestação de baixo risco na cidade de Ponta Grossa, Paraná. A análise se deu mediante análise de conteúdo (BARDIN, 1977) seguindo suas 3 etapas:

1- Pré-Análise, que consiste no primeiro contato com o material, preparação do material e formulação de hipóteses; 2- Exploração do Material, nesta fase são realizados os primeiros recortes nos relatos em unidades; 3- Tratamento dos Resultados, Inferência e Interpretação, a última fase corresponde a categorização, onde então é possível realizar a análise reflexiva e verificar os pontos comuns.

A pesquisa seguiu os aspectos éticos da resolução 196/96, com assinatura do Termo de Consentimento Livre e Esclarecido e teve aprovação do Comitê de Ética em Pesquisa da Universidade Estadual de Ponta Grossa, sob o Parecer número 165/2011. Salienta-se que o parecer utilizado é o mesmo usado pelo Projeto CPE, pois trata-se de puérperas participantes do mesmo. 


\section{RESULTADOS E DISCUSSÃO}

Para caracterizar o perfil das participantes do estudo, inicialmente retratou as condições sócio-demográficas e obstétricas das mesmas, visando enriquecer a pesquisa realizada.

Obteve-se participação de 11 puérperas no estudo, com idade entre 15 a 36 anos, tendo a média, 21 anos. Já quanto ao o estado civil, 5 (45,45\%) das puérperas conviviam com o parceiro, $4(36,36 \%)$ eram casadas e apenas $2(18,18 \%)$ declararam serem solteiras. Assim, observa-se que $9(81,81 \%)$ das mesmas tiveram o convívio com o parceiro e pai do bebê, preservando o contato da tríade familiar mãe-pai-filho.

Quanto a escolaridade, $5(45,45 \%)$ delas não concluíram o ensino fundamental, onde apenas $1(9,09 \%)$ puérpera declarou ter finalizado o mesmo, como também, o ensino médio, 2 $(18,18 \%)$ puérperas o concluíram e $3(27,27 \%)$ não o completaram. Quanto ao trabalho, 7 $(63,63 \%)$ delas não possuíam emprego, declararam trabalhar no lar e as demais, $3(27,27 \%)$ estavam com carteira assinada, sendo $1(9,09 \%)$ sem carteira, no qual a renda familiar apresentou-se entre 1 a 2 salários mínimos. Fazendo uma analogia, pode-se relacionar o trabalho domiciliar $(63,63 \%)$ das puérperas com a baixa concretude dos estudos (ensino fundamental e médio - 72,72\%).

Já o perfil obstétrico, a característica se constituiu de multigestas, sendo $9(81,81 \%)$ das puérperas, porém das 11 puérperas entrevistadas, $4(36,36 \%)$ eram primíparas e 7 $(73,73 \%)$ multíparas. Ao serem questionadas sobre experiência com amamentação no filho anterior observou-se que $5(45,45 \%)$ nunca haviam amamentado, sendo que das mulheres que haviam realizado o aleitamento materno, ou seja 6 delas, 3 (27,27\%) relataram realizá-lo por 6 meses em Aleitamento Materno Exclusivo (AME) e as demais 3 mulheres não completaram os 6 meses de AME, ocasionando então o desmame precoce.

O pré-natal por sua vez foi realizado por $8(72,72 \%)$ das puérperas com mais de 6 consultas e $3(27,27 \%)$ realizaram o pré-natal, porém inferior a 6 consultas. Entretanto, ao averiguar a educação em saúde oferecida no pré-natal, observou que as puérperas $(n=11$, $100 \%$ ) não foram orientadas a preparar as mamas para o aleitamento materno e 6 (50\%) delas relataram não ter recebido nenhum esclarecimento frente ao aleitamento materno, sendo que 
somente uma $(9,09 \%)$ relatou receber orientações do médico e do enfermeiro na unidade de saúde.

Diante disso observa-se que o perfil pode ser caracterizado como pertencente ao extrato socioeconômico baixo, evidenciado pela baixa escolaridade, renda familiar entre 1 a 2 salários mínimos e ausência de trabalho formal com carteira assinada. Nesse contexto, cabe destacar que o enfermeiro precisa realizar além da assistência de enfermagem puerperal, mais imprescindível oferecer a mulher, a educação em saúde, visando a promoção da autonomia materna diante das modificações com seu corpo, cuidados com o recém-nascido e orientações sobre o aleitamento materno.

Sendo assim, como dispõe a Lei do Exercício Profissional, Cofen Lei no 7.498 artigo 11 ao enfermeiro cabe, a responsabilidade da consulta de enfermagem a puérpera, na qual devem ser enfatizadas as ações educativas em saúde (BRASIL, 1986). Portanto, o Projeto Consulta Puerperal de Enfermagem se enquadra por oportunizar aos acadêmicos de enfermagem a realização da promoção em saúde com mulheres no pós-parto, esclarecendo dúvidas, principalmente sobre o aleitamento e cuidados com os problemas mamários.

\section{O Aparecimento dos Traumas Mamilares no Pós-Parto: vivências de puérperas}

$\mathrm{O}$ ato de amamentar é uma prática cultural, muito importante no período pós-parto, no qual o leite materno torna-se o alimento ideal ao recém-nascido e todas as atenções voltam-se ao binômio mãe/bebê. Desta forma, podem aparecer problemas no decorrer dessa prática que podem interferir diretamente na vida do binômio, destacando os traumas mamilares, que podem ser definidos como a ruptura, alteração ou descontinuidade da pele da região do mamilo e aréola (RIBEIRÃO PRETO, 1998; COCA et al, 2009).

Entretanto as principais causas e fatores para o surgimento dos traumas estão relacionados com os posicionamentos incorretos da criança e da mãe, controle inadequado da sucção, preensão incorreta no mamilo ou aréola pelo bebê, e ainda, as alterações anatômicas nos mamilos (COCA et al, 2009).

Nessa perspectiva, destacam-se as fissuras, edema, eritema, bolhas (BRASIL, 2011), além disso, caracteriza-se por causar à mulher, algum grau de dor ou desconforto durante a mamada, contribuindo assim para o desmame precoce da amamentação (COCA et al, 2009). Por meio destas manifestações e sintomas, pode-se classificar o trauma de acordo com a sua forma de apresentação e sintomatologia. 
Inicialmente, destaca-se o mamilo fissurado, no qual apresenta uma lesão de continuidade na epiderme mamilar, com a forma de fenda, a extensão da fissura determina sua classificação em pequena, média ou grande, além disso, considera-se a intensidade com que a mãe relata dor ao amamentar (RIBEIRÃO PRETO, 1998). Desta forma, entre as puérperas entrevistadas foi possível perceber em seus relatos, que estavam passando pelo inicio da formação da fissura mamária, onde se observa o uso de termos populares para se referir ao problema mamário, como bico partido, rachado, entre outros. Seguem alguns dos relatos:

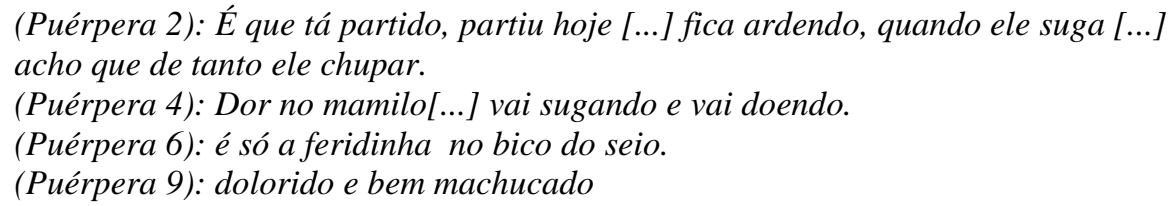

Outra forma de manifestação do trauma mamilar bastante comum é o mamilo dilacerado, muitas vezes descrito como fissura de aspecto dilacerado, neste, é comum que a pressão sobre o mamilo forme um trauma de característica dilacerada ("rasgado"), ocorrendo principalmente na região da aréola (RIBEIRÃO PRETO, 1998). Seguem abaixo os relatos:

(Puérpera 5): meu seio ele além machucado, tá ressecando[...] Daí vai puxar dói (Puérpera 8): ta rachado um pouco o seio. Doendo bastante

Há ainda o trauma descrito como vesicular (RIBEIRÃO PRETO, 1998), com a formação de vesículas devido a privação da circulação sanguínea no local, ocorrendo então a fragilização dos capilares e formação das vesículas, com a presença do exudato, conforme se observa no relato da puérpera 3 . Outra característica importante do trauma vesicular é o sintoma de ardor durante e após a amamentação, descritos nos depoimentos de puérperas 7 e 10.

\footnotetext{
(Puérpera 3): Quando eu amamentava a outra saia umas bolinhas vermelhas no meu peito, aí dói muito[...] sinto muita dor.

(Puérpera 7): to com uma ardenciazinha.

(Puérpera 10): ardendo no bico do peito.
}

Assim, por meio dos depoimentos acima, observa-se, o uso de termos populares para se referenciar aos traumas mamilares, sendo descritos como; "bolinhas vermelhas", "feridinha", "rachado", "partido" (BRASIL, 2011). Quanto ao sintoma, dor, este foi relatado por todas as participantes, de acordo com a intensidade pela qual a mulher julgava, além de referenciar muitas vezes a dor como uma ardência durante a mamada ou após, sendo que este sintoma relaciona-se principalmente com o trauma mamário vesicular. 
Portanto, cabe aos profissionais de saúde no decorrer do ciclo gravídico-puerperal, aqui destacando o profissional enfermeiro, a esclarecer as dúvidas e inquietudes com educação em saúde frente ao aleitamento materno e suas complicações, como os traumas mamilares, pois estes, se não orientados e tratados, podem proporcionar o aparecimento do desmame precoce, ainda mais quando, somado com as práticas culturais, podendo exacerbar os sintomas.

\section{A Prática do Aleitamento Materno e os Traumas Mamilares: educação em saúde no cotidiano do enfermeiro}

$\mathrm{Na}$ literatura atual são encontradas várias descrições de tratamentos preventivos ou curativos para os traumas mamilares, entre eles, o uso da lanolina, e o dito tratamento seco, no qual a mulher deve expor os seios a luz artificial ou solar, para que estes permaneçam secos. No entanto, esse tratamento não tem mais indicação, pois pode ocorrer o retardo da cicatrização das feridas mamilares (BRASIL, 2011).

Atualmente, a principal forma de tratamento para as fissura consiste no tratamento úmido, visando a formação de uma camada protetora sobre o mamilo, sendo que esta, impede a desidratação das camadas mais profundas da pele, além disso, a cicatrização das fissuras demonstrou ser mais eficiente quando as camadas se mantêm úmidas (BRASIL, 2009). Desta forma recomenda-se que a mulher aplique o próprio leite materno sobre o mamilo machucado.

Diante do exposto, identificou-se nos relatos das puérperas que o tratamento úmido é utilizado e conhecido pelas mesmas, segundo relatos abaixo, sinal de que houve a educação em saúde, pois tal tratamento é o recomendado pelo Ministério da Saúde, diante do surgimento dos problemas com traumas mamilares.

\footnotetext{
(Puérpera 2): Lavar com água e sabão, na hora do banho e quando estiver rachadinho passar o leite, envolta do seio.

(Puérpera 5): Agora eu vou passar só o leite do peito.

(Puérpera 6): Eu espremo o seio até sai um pouco de leite e passo no bico e dou pra ela mamar.

(Puérpera 7): Eles falaram pra passar o leite antes de amamenta, só o leite. (Puérpera 8): eu to tirando um pouco do leite e passando no mamilo.
}

Com tais relatos, nota-se que o tratamento úmido tem sido a maneira como os profissionais de saúde estão orientando puérperas mediante o surgimento dos traumas mamilares, porém, deve ter o cuidado na realização da higienização das mamas, verificando 
ser importante a não utilização de sabonetes, sabão ou álcool, pois estes removem a proteção do mamilo (BRASIL, 2011).

Contudo, ainda são encontradas mulheres que recorrem as práticas culturais como principal meio de tratar seus problemas mamários, conforme verifica-se nos depoimentos abaixo. Estes cuidados são passados através dos conhecimentos populares que integram a cultura da medicina caseira. É importante que os profissionais de saúde, destacando o enfermeiro, que integrem tais práticas às orientações preconizadas, para desmitificá-las sem apontá-las como práticas prejudiciais, promovendo o autocuidado consciente da puérpera e do seu contexto social.

\footnotetext{
(Puérpera 1): me ensinaram a passar a casca de banana (Puérpera 4): pomadinha, e lavando[...] e a casca da banana que corta em pedacinho pequeno e coloca em cima do bico do seio

(Puérpera 5): eu passei um pouco de pomada[...] coloquei o bico de silicone pra ver se eu conseguia, ele misturava com sangue.

(Puerpera 8): quando partiu meu peito, me ensinaram a colocar tipo hortelã, dá uma fritadinha assim no azeite e coloca no bico do peito.

(Puerpera 9): Casca de banana e fígado[...] pega a raspa da banana, põe a casca em cima[...] põe o fígado ali[...]Daí você nunca mais pode come.
}

Lastimavelmente, o uso abusivo de muitas destas práticas podem acarretar problemas à mulher, pois pode facilitar o surgimento de infecções, ou o surgimento de outros problemas mamários, como o ingurgitamento. A educação em saúde concomitante com o resgate de práticas culturais no pós-parto, esclarecendo de maneira clara, científica num linguagem popular, é o veículo no qual ocorre a promoção da saúde materna e neonatal.

Uma dessas práticas é o uso da casca da banana, que deve ser desestimulada, visto que, seu uso não possui comprovação de eficácia, além de ser fonte de transmissão de bactérias contribuindo para o início do processo infeccioso e ainda causar reações alérgicas (GIUGLIANI, 2006; BRASIL, 2009).

No entanto, nos relatos das puérperas 4 e 5 notou o uso de pomadas no tratamento dos traumas mamários, porém, também é contra indicado, pois podem manifestar reações de sensibilidade mamilar à pomada, assim como, a perda das propriedades de lubrificação e bacteriostáticas da pele. Entretanto atualmente observa-se a recomendação de uso da pomada a base de lanolina, para o controle da hidratação dos mamilos e tratamento de fissuras, devido suas propriedades que auxiliam na cicatrização das lesões no mamilo (COCA, ABRÃO, 2008). 
Diante disto, surgiu uma controvérsia entre, as recomendações preconizadas e o uso indevido das pomadas no tratamento dos traumas mamários, e assim, propuseram que a lanolina seja usada com cautela, visto a limitação nos estudos que comprovem sua eficácia (BRASIL,2011).

Outro produto utilizado nos traumas são os bicos de silicone (concha protetora) utilizados quando surgem as fissuras mamárias, para evitar o contato com a lesão (BRASIL,2009), entretanto, tais conchas tendem a tornar a região mamilar úmida e com temperatura elevada, propiciando local favorável ao surgimento da candidíase mamilar (MENEZES, 2010). Sendo assim, não são observados benefícios do uso de protetores intermediários (bico ou concha de silicone) para o tratamento ou prevenção do trauma mamilar, possibilitando efeitos danosos aos mamilos (GIUGLIANI, 2006).

Duas práticas descritas pelas puérperas 8 e 9 não foram encontradas na literatura, a partir de busca em bases de dados, podendo desta forma concluir ser uma pratica cultural local. Assim, o uso da hortelã é importante considerar que o desconhecimento da procedência desta pode acarretar riscos de infecções secundárias e a prática de frita-lo antes de colocar sobre a fissura pode acarretar em queimaduras, visto que, o tecido mamilar já se apresenta sensibilizado. Quanto ao fígado não foram encontrados estudos que demonstrem seu auxílio no tratamento de fissuras.

\section{Outras Práticas Culturais}

Foram descritas ainda práticas culturais relacionadas com o ingurgitamento mamário, mamilos invertidos ou planos e a crença popular do pouco leite. O ingurgitamento mamário é definido como, a retenção anormal de leite, apresentando como sintoma a dor na mama, hipertermia e hiperemia (RIBEIRÃO PRETO, 1998). Há duas formas principais de diferenciação (BRASIL, 2011), sendo-as; o ingurgitamento considerado discreto, aquele que demonstra que está havendo a produção láctea, e o ingurgitamento patológico, no qual ocorre a distensão da mama, que estão edemaciadas e congestionadas, surgindo então o desconforto devido o acúmulo de leite, que também se altera tornando-se mais viscoso, e adquirindo o nome popular de leite empedrado.

Desta forma, quando questionadas sobre o que era feito para tratar o ingurgitamento mamário, ou leite empedrado, foram observados os seguintes relatos das puérperas. 
(Puerpera 3): me ensinaram a fazer compressa, fazer assim oh \{demostrou a massagem\}

(Puerpera 7): esquentar uma toalhinha, água morna e coloca, umas compressazinhas que amolece o leite se ele estiver empedrado.

(Puérpera 9): Eu ponho pano molhado Pra vê se abaixa um pouco.

(Puérpera 10): tirando um pouco de leite, pra ficar menos pesado.

Com o aparecimento do ingurgitamento mamário torna-se importante que o enfermeiro saiba orientar a mulher quanto ao manejo deste problema. No entanto, nota-se que comumente se orienta o uso da prática de compressas quentes ou mornas para aliviar o sintoma da dor, onde o calor local promove a vasodilatação e aumento na circulação sanguínea, reduzindo assim, o edema e auxiliando na drenagem do leite, entretanto, ocorre o aumento no metabolismo, causando o aumento na produção e volume de leite nas mamas (RIBEIRÃO PRETO, 1998; GIUGLIANI, 2006).

No entanto, um manejo importante a ser realizado é a prática da ordenha manual, na qual favorece o esvaziamento da mama, constituindo-se fundamental para o manejo das mamas ingurgitadas, por reduzir a pressão nos alvéolos, possibilitando a drenagem da linfa e garantindo a produtividade láctea (GIUGLIANI, 2006). Recomenda-se a realização de mamadas frequentes em livre demanda, massagem com movimentos circulares das mamas, uso de medicamentos analgésicos ou antiinflamatórios, e compressos frias logo após as mamadas por um período de 15 a 20 minutos (BRASIL, 2009).

Quanto a formação dos mamilos (planos, invaginados, invertidos, entre outros) notou que, independente de serem mamilos planos ou invertidos, estes irão apenas dificultar nos primeiros dias a amamentação, pois a criança mama o peito e não somente o bico, tornando efetiva a mamada, onde o bebê abocanha bico e aréola (BRASIL, 2011).

Contudo, pelo relato da puérpera 11, ainda ocorrem orientações de práticas para realizar a exteriorização do mamilo invertido.

(Puérpera 11): [...] ele tem que puxar com a seringa.

Tal prática consiste em adaptar uma seringa de 10 a $20 \mathrm{~mL}$, cortando a saída estreita e inserindo o êmbolo na mesma. Todavia existem diversas técnicas para realizar a protração do mamilo, porém é importante que a realização desta ocorra apenas antes das mamadas, sendo desaconselhável o uso desta no período pré-natal (BRASIL, 2009; GIUGLIANI, 2006).

Outro fato a ser considerado, é a crença da pouca quantidade de leite, instaurada pela insegurança materna diante do choro da criança, que normalmente é associado a fome 
(MARQUES, COTTA E PRIORE, 2011). Desta forma, leva-se a acreditar que, quantidade e qualidade do leite é de pouca produção ou ruim, mistificando a prática do aleitamento materno. Nesse contexto, surgem as práticas baseadas na cultura popular, na resolução da pouca produção láctea, para isto, são usados diversos alimentos e bebidas, considerados, auxiliares, no processo para aumentar a quantidade de leite (ICHISATO, SHIMO, 2006).

Assim, este estudo encontrou nos relatos abaixo, mulheres que conheciam ou utilizaram práticas culturais para aumentar a quantidade de leite.

\footnotetext{
(Puérpera 3): Me ensinaram que é bom tomar a cerveja preta, tomava muito pra juntar leite. E agora vo pra casa vou tomar a cerveja preta porque é bom. Me falaram que a canjica também é bom pra juntar leite. (Puerpera 5): Tomar chá, qualquer tipo de chá. A famosa fervida que eles falam. A cerveja preta, mas isso eu não cheguei a tomá, ouvi fala.

(Puerpera 8): [...] me deram bastante chá pra juntar leite, chá de ameixa bastante coisa pra mim, e chegou a encher mesmo[...] não sei se estimula, vai da gente, mas resolveu.
}

Diante dos relatos, a prática da ingestão da cerveja é muito difundida pelas práticas culturais, onde há componentes da bebida que causam o aumento do leite, porém não tem relação com o teor alcoólico (GAÍVA, MEDEIROS, 2006). A canjica, descrita pela puérpera 3, consiste em ser um alimento rico em amido, que produz a glicose, a qual é usada na produção do leite (ICHISATO, SHIMO, 2006).

Verificou-se também, a prática de consumir maior quantidade de líquidos, por meio de chás ou mesmo pela crença de que, determinadas ervas e plantas possuem efeitos sobre o aumento na lactação, sendo observados os benefícios psicológicos e aumentando a confiança da mulher (GAÍVA, MEDEIROS, 2006). Entretanto não se recomenda a ingestão excessiva de líquidos, pois não ocorre o aumento na produção de leite, ocorrendo até mesmo o efeito contrário (BRASIL,2011; GIUGLIANI, 2006; GAÍVA, MEDEIROS, 2006).

\section{Da ajuda para a superação dos problemas mamários}

Se a amamentação é uma prática muito influenciável pelo meio onde a mulher vive, pode-se destacar que para o bom desenvolvimento é importante que a puérpera obtenha o apoio e incentivo da sua família, comunidade e profissionais de saúde (BRASIL, 2009). Diante da ocorrência dos problemas mamários, torna-se importantíssimo a ajuda de outra pessoa, cabendo então aos familiares e pessoas mais significativas a puérpera ser uma fonte de apoio, quanto aos profissionais de saúde devem figurar como uma fonte de informações (SILVA, SANTIAGO E LAMONIERI, 2012). 
Foi possível identificar através das entrevistas, as pessoas que influenciaram e realizaram o apoio as puérperas na realização dos cuidados diante dos problemas relacionados com a mama. Sendo assim, observam-se aquelas que mencionaram como principal seu apoio o contexto familiar.

(Puerpera 3): Foi minha cunhada que me ensinou, porque ela já teve 4[...]

(Puerpera 4): Ah isso é de família[...]

(Puerpera 7): Minha mãe falou [...] Aprendi com minha mãe, ela que falou [...]

Nesse contexto é importante obter o envolvimento das pessoas que convivem diariamente com as puérperas, como as avós e outros familiares, pois estas pessoas têm a oportunidade de influenciar as mulheres na amamentação e nos cuidados com a mama no puerpério (BRASIL, 2011). A vivencia da amamentação é acompanhada pelas avós, sogras, irmãs e tidas como exemplo, onde o conhecimento empírico tende a originar-se do aprendizado adquirido pelas práticas desenvolvidas no cuidado popular, baseados em mitos e crenças (FROTA et al, 2009).

Contudo, houve também relatos de mulheres que receberam ajuda de pessoas do meio em que vive que estão inseridas na mesma comunidade.

\author{
(Puerpera 1): Minha vizinha. \\ (Puerpera 7):[...] e todo mundo fala [...] \\ (Puerpera 9): A mulher falou que diz não podia [...]
}

Cabe aqui destacar que a sociedade, no papel dos vizinhos, também constitui importante fonte de auxilio na transmissão de praticas cultural a puérpera, estabelecendo redes de trocas de conhecimentos da medicina caseira entre as famílias, nas suas relações de vizinhança (TOMELERI, MARCON, 2009).

Observou que muitas das mulheres apontaram como principais fontes de auxilio as orientações realizadas por profissionais de saúde. É importante que o profissional de saúde, aqui destacando o enfermeiro, saiba aliar os conhecimentos e habilidades para o manejo do aleitamento materno, bem como, dos problemas que ocorrem nas mamas, sendo que a principal forma de transmitir o conhecimento científico a mulher é através do aconselhamento, onde o profissional deve ouvir e dialogar com a puérpera, demonstrando as melhores opções para o cuidado (BRASIL, 2009).

(Puerpera 2): A doutora, a pediatra de hoje.

(Puerpera 4): [...] a pomada foi o doutor, o médico.

(Puerpera 5): O próprio médico tinha me falado. 
(Puerpera 6):[...] eles já me ensinaram no hospital já, porque já partiu no hospital. (Puerpera 7):[... ] lá no posto também, entregaram um encartezinho explicando[...] (Puerpera 8): [...]no hospital que eles deram, orientaram e eu to aprendendo. (Puerpera 10): Os enfermeiros daqui.

Entretanto é comum observar que os profissionais veem a amamentação como um ato biológico e instintivo, sem verificar as necessidades pessoais das mulheres e suas dificuldades (MARQUES, COTTA E PRIORE, 2011). Destes destaca-se o profissional enfermeiro o qual possui o cuidado estabelecido por métodos científicos como base para a profissão e tende a desconsiderar a cultura envolvida no cuidado popular, gerando conflitos com a puérpera e sua família ao desprezar as práticas culturais presentes naquele núcleo familiar (TOMELERI, MARCON, 2009).

Torna-se assim importante que os profissionais da enfermagem aprendam a ver a puérpera como um ser integral, que possui um contexto de vivencia familiar e sociocultural, diferente da visão fragmentada e biológica, possibilitando assim resultados mais positivos na saúde da população (VIEIRA et al, 2010). Para isto é importante que o profissional adote a postura de apoiar e incentivar a mulher que amamenta, por meio das ações de educação em saúde, enfatizando os cuidados importantes com a mama, realizando por meio de sugestões a mulher (BRASIL, 2009).

\section{Do desmame precoce}

O desmame se define como, a complementação da alimentação da criança que estava realizando a amamentação exclusiva, e passa pela influencia de diversos fatores como os relacionados a pouca idade materna, experiência com o aleitamento, escolaridade, além daqueles relacionados com as dificuldades iniciais enfrentadas na prática de amamentar, como a presença dos traumas mamários, ingurgitamento e crença do pouco leite (ARAÚJO et al, 2008).

Quando questionadas sobre a necessidade de interrupção da amamentação, verificou-se pelos depoimentos das puérperas que diante do surgimento dos problemas mamários, essas foram orientadas a realizar a complementação da amamentação com outro tipo de leite, sendo referenciado principalmente o leite NAN. E verifica-se ainda que, a orientação partiu do profissional de saúde, evidenciando nos relatos o profissional médico.

(Puerpera 2): Eu fui no médico, e ele me orientou a dar o Nan, que era o único leite que eu podia dar.

(Puerpera 5): Daí parei a amamentação, e comecei a esvazia, e o leite começou a diminuir. Eu comecei com o leite especial, o NAN. Depois fui pro nestogeno,[...] 
mas isso com intervalo de um mês. Daí quando ele tava com 4 meses eu passei pro leite de vaca.

(Puerpera 11): O NAN. Acho que foi o médico.

É possível concluir que apesar das recomendações de oferecer apoio e orientações no manejo dos problemas mamários, o mesmo não vem ocorrendo como se espera. Contudo observou-se ainda, com o relato da puérpera 6 , que realizou a complementação precoce da alimentação, pois a mesma não tinha a experiência e conhecimento quanto a importância do aleitamento exclusivo.

(Puérpera 6): Foi por falta de experiência, foi dando chazinho, chuquinha, ele foi largando e secando o leite.

Assim, a prática do aleitamento é o resultado de experiências individuais, influenciado pelo ambiente da puérpera, e costuma-se repetir a experiência vivida por outra mulher ( FROTA et al, 2009), que está próxima e é considerada por esta um exemplo.

\section{Da continuação do aleitamento materno}

Ainda se observou neste estudo com os depoimentos de puérperas que, mesmo diante das dificuldades causadas pelos problemas mamários, estas viam que a prática do aleitamento materno deveria continuar, não realizando a introdução de outros tipo de leite.

\footnotetext{
(Puerpera 1): Continuaria.

(Puerpera 3): Ah não posso para, porque dá dó, mas dói muito, mas não parei.

(Puerpera 4): Continuei, mesmo assim. Até tentei dar uma mamadeira com NAN

$[\ldots]$

(Puerpera 8): Eu não parei. Continuei, mesmo saindo sangue, doendo [...]

(Puerpera 9): Eu to sentindo dor, mais não vou parar.

(Puerpera 10): To continuando, só com o leite materno.
}

A ocorrência deste resultado é importante, pois demonstra que o apoio e orientações realizadas pelos profissionais da saúde foram efetivos para a decisão da mulher em praticar o aleitamento materno exclusivo. Entretanto, os problemas mamários são fatores que podem desencadear e contribuir para o desmame, mas não um determinante isolado (ARAÚJO et al, 2008). 


\section{CONSIDERAÇÕES FINAIS}

A identificação das práticas culturais relacionadas com os problemas mamários decorrentes no período do aleitamento materno possibilita verificar como ainda nos dias de hoje o conhecimento popular está muito presente no cuidado cotidiano presente em todas as sociedades, sendo aqui representada pela figura da puérpera.

Verifica-se que mesmo com a participação em grupos de gestante ou realizando as consultas de pré-natal, as mulheres não realizaram o preparo das mamas, deixando assim a dúvida sobre como estão sendo realizadas as orientações sobre o aleitamento materno e sobre a prevenção dos traumas mamilares. Sendo observado que as orientações de cuidados com as mamas são realizadas apenas no pós-parto, na maternidade, ou diante do surgimento de problemas mamários.

Mesmo observando que grande parte das mulheres demonstrou conhecimento adequado sobre o manejo principalmente dos traumas mamilares, é importante observar que outras puérperas demonstraram significantes conhecimentos sobre cuidados baseados na medicina caseira para tratar o problema apresentado.

Quanto a introdução precoce de outros alimentos, observou-se neste estudo que ao procurar por auxílio de profissionais de saúde no momento em que apresentava dificuldade com a amamentação, as puérperas receberam a orientação de iniciar a introdução do leite NAN pelo profissional médico. Verificando assim, que também há falta do preparo dos profissionais para auxiliar a mulher lactante e orientar sobre os benefícios da amamentação exclusiva até os 6 meses, e superação dos problemas mamários.

Desta forma é importante que o profissional enfermeiro saiba reconhecer que a mulher como integrante da sociedade possui características próprias, resultado de suas experiências e vivência em um ambiente social responsável por moldar muitos dos comportamentos. Além de tornar necessária a superação da visão da amamentação como função materna biologicamente determinada, pois ao saber da influência cultural sobre a mulher é possível reconhecer a necessidade de se trabalhar agregando os conhecimentos científicos e os saberes populares que envolvem a amamentação, para que a própria puérpera saiba reconhecer as práticas de origem cultural que tendem a prejudicar e comprometer as mamas, além de contribuir negativamente em sua saúde. Sendo importante que o enfermeiro saiba oferecer suporte e apoio ao problema das mamas, como também o suporte emocional, para auxiliar na superação da ansiedade e medo que pode ocorrer neste período. 
Diante disso, é importante revisar a forma como esses profissionais realizam as orientações da importância da amamentação, por ser considerado promotor de saúde o enfermeiro deve atuar esclarecendo as dúvidas que surgem com o período da amamentação, reorganizando a forma como são realizadas as ações de promoção do aleitamento materno, sendo necessário envolver também os pais e avós.

\section{REFERÊNCIAS}

ARAÚJO, O.D. et al. Aleitamento materno: fatores que levam ao desmame precoce. Rev. bras. enferm., Brasília, v. 61, n. 4, ago. 2008.

BARDIN, L. Análise de Conteúdo. Lisboa (POR): Edições 70, 1977.

BRASIL. Ministério da Saúde. Secretaria de Atenção à Saúde. Departamento de Ações Programáticas e Estratégicas. Atenção à saúde do recém-nascido: guia para os profissionais de saúde, Brasília, 2011.

Ministério da Saúde. Secretaria de Atenção à Saúde. Departamento de Atenção Básica. Saúde da Criança: nutrição infantil: aleitamento materno e alimentação complementar., Brasília, 2009.

Lei n. 7.498, de 25 de junho de 1986. Dispõe sobre a regulamentação do exercício da enfermagem e dá outras providências. Diário Oficial da União, Brasília, Seção 1:10, 26 jun. 1986.

COCA, K.P. et al. A posição de amamentar determina o aparecimento do trauma mamilar?. Rev Esc Enferm USP, São Paulo, v. 43, n. 2, p. 446-452. 2009.

COCA, K.P.; ABRÃO, A.C.F.V. Avaliação do efeito da lanolina na cicatrização dos traumas mamilares. Acta Paul Enferm., São Paulo, v. 21, n. 1, p. 11-16. 2008.

FROTA, M. A. et al . Práticas culturais sobre aleitamento materno entre famílias cadastradas em um Programa de Saúde da Família. Rev. esc. enferm USP, São Paulo, v. 43, n. 4, p. 895-901, Dez. 2009.

GAIIVA, M.A.M.; MEDEIROS, L.S. Lactação Insuficiente: uma proposta de atuação do enfermeiro. Cienc Cuid e Saúde, Maringá, v. 5, n. 2, maio/ago. 2006.

GIUGLIANI, E.R.J. Aleitamento Materno: principais dificuldades e seu manejo. In: Duncan BB, Schimidt MI, Giugliani ERJ e colaboradores. Medicina Ambulatorial: Condutas de atenção primária e baseadas em evidência. Porto Alegre: Artmed; 2006. p. 232- 239. 
ICHISATO, S.M.T.; SHIMO, A.K.K. Vivência da amamentação: lactogogos e rede de suporte. Cienc Cuid e Saúde, Maringá, v. 5, n. 3, set/dez. 2006.

LARAIA, R.B. Cultura: um conceito antropológico. 14. ed. Rio de Janeiro: Jorge Zahar, 2001.

MARQUES, E.S.; COTTA, R.M.M.; PRIORE, S.E. Mitos e crenças sobre o aleitamento materno. Ciênc. saúde coletiva., Rio de Janeiro, v. 16, n. 5, mai 2011.

MENEZES, T.M.X. Candidíase Mamilar: as interfaces entre a cultura e o cuidado. $R$. pesq.: cuid. Fundam. online., v. 2 (Ed. Supl.), out/ dez. 2010.

MONTEIRO, J.C.S.; NAKANO, A.M.S.; GOMES, F.A. O aleitamento materno enquanto uma prática construída. Reflexões acerca da evolução histórica da amamentação e desmame precoce no Brasil. Invest Educ Enferm., v. 29, n. 2. 2011.

NEVES, J.L. Pesquisa Qualitativa- Características, usos e possibilidades. Caderno de pesquisas em administração. v. 1, n. 3, 1996.

RIBEIRÃO PRETO. Secretaria Municipal da Saúde. Núcleo de Aleitamento Materno da Escola de Enfermagem de Ribeirão Preto- USP. Programa Aleitamento Materno. Manual de Procedimentos: Prevenção e tratamento das intercorrências mamárias na amamentação. Ribeirão Preto: SMS/ NALMA- SP, 1998.

SILVA, B.T.; SANTIAGO, L.B.; LAMONIER, J.A. Apoio paterno ao aleitamento materno: uma revisão integrativa. Rev Paul Pediatr., v. 30, n.1, p. 122-130. 2012.

TOMELERI, K.R.; MARCON, S.S. Práticas populares de mães adolescentes no cuidado aos filhos. Acta Paul Enferm., São Paulo, v. 22, n. 3, p. 272-80, jun. 2009.

VIEIRA, F. et al . Diagnósticos de enfermagem da NANDA no período pós-parto imediato e tardio. Esc. Anna Nery, Rio de Janeiro, v. 14, n. 1, p. 83-89, Mar. 2010.

\section{RECEBIDO EM: 17/09/2013.}

APROVADO EM: 21/09/2015. 